\title{
An interactive and participative approach to water quality management in agro-rural watersheds
}

\author{
S Mtetwa* and CF Schutte \\ Department of Chemical Engineering, University of Pretoria, Pretoria 0001, South Africa
}

\begin{abstract}
An interactive and participative approach to involve and mobilise rural communities in water quality control programmes was investigated. Agro-rural watersheds are experiencing serious environmental degradation mainly because of inappropriate land use practices due to various competing and opposing priorities in the community. The communities tend to concentrate on availability of land and water for their activities regardless of the state of that resource. The methodology is designed to bring awareness to the rural farmers of the amounts of pollutants they contribute to a river system and the benefits of adhering to good land-use and farming practices both in terms of production and environmental protection. It is based on a pilot project, dealing with an agro-rural watershed in a semi-arid developing area. A strong emphasis was put on stakeholder participation, an area neglected by many researchers. It became clear that pollutant flushes from the catchments are influenced by many factors, of which agricultural practices is only one.
\end{abstract}

\section{Introduction}

Most countries in the semi-arid Southern African region are facing difficult and severe environmental problems, which include degradation of water sources, soil erosion and destruction of natural ecosystems like wetlands. These problems cut across the various water use sectors including urban, industrial and mining, commercial and communal farming. The monitoring and control of these problems are well developed in most sectors. The communal sector, however, has been neglected; yet in many cases it contributes significantly to environmental degradation.

The major problems in the rural areas include overgrazing, siltation, poor agricultural practices and poor land management, emanating from technological, economical and socio-political problems, with numerous actors, differing goals and perceptions (Ongley 1998; Fedra 1984).

In the main the pollutants from rural settings tend to be of a diffuse nature and are difficult to identify, isolate or control (Hoffmann, 1994). In managing diffuse pollution, the focus should be on controlling the activities at source and along the delivery pathways to the receiving water, i.e. a source-directed approach based on best management practices. This requires readily available information and a high level of community participation.

However, in most parts of rural Southern Africa the following problems are common (Shela, 1993):

- Information is not readily available

- Literacy levels are low

- There is lack of adequate scientific understanding

- There is lack of public and political support

- Severe economic constraints are prevalent

- Policies and legal instruments are out-dated

- Institutional arrangements are poor.

* To whom all correspondence should be addressed. Current address: Zimbabwe National Water Authority, Water Quality Section, PO Box CY 617, Causeway, Harare, Zimbabwe

疅 +263 4 793193; fax +2634 700597; e-mail: mtetwa@utande.co.zw Received 19 August 1999; accepted in revised form 26 March 2002.
All these factors make the management of diffuse pollution in the developing arid regions a challenging exercise. It calls for new approaches that are relevant, effective and sustainable, and that will increase effective decision-making in data-poor environments. Recognition of this need prompted the idea of investigating appropriate approaches for solving this problem.

The solution to diffuse pollution requires a comprehensive approach to water resources management. This approach recognises the river basin as the appropriate unit for managing water quality, quantity and ecosystem integrity (Duda, 1993). The river basin proposed for this study is the Muda River catchment, which forms the headwaters of the Sanyati catchment in Zimbabwe.

The main objective of this project was to investigate appropriate approaches for managing the water quality in the rural areas of developing semi-arid regions where various adversarial factors exist. This was done by focusing on effective community-based activities such as environmentally sustainable agricultural practices. This paper reports on the interactive and participative approaches that were implemented and the resulting effects on the environment. The effectiveness of the management options is measured both in economic and environmental terms: In economic terms by determining the gain or loss of yield due to the various alternatives and in environmental terms by determining the quality of the water being flushed from the sub watershed. Crowder et al. (1985) showed that farm income levels could be maintained by adopting conservation tillage practices or by crop rotation.

\section{The study area}

The Muda River catchment was chosen for this study because it represents a typical rural setting in a developing country, which is predominantly a farming area and exhibits little or no point sources of pollution. The catchment is situated in the Mupfure upper catchment between $18^{\circ} 17^{\circ} \mathrm{S}, 18^{\circ} 11^{\prime} \mathrm{S}$ and $30^{\circ} 59^{\circ} \mathrm{E}, 31^{\circ} 14^{\circ} \mathrm{E}$. It covers an area of $206.26 \mathrm{~km}^{2}$ and transverses part of Chiota Communal Lands in its upper part and passes through some smallscale commercial farms in its lower parts. 


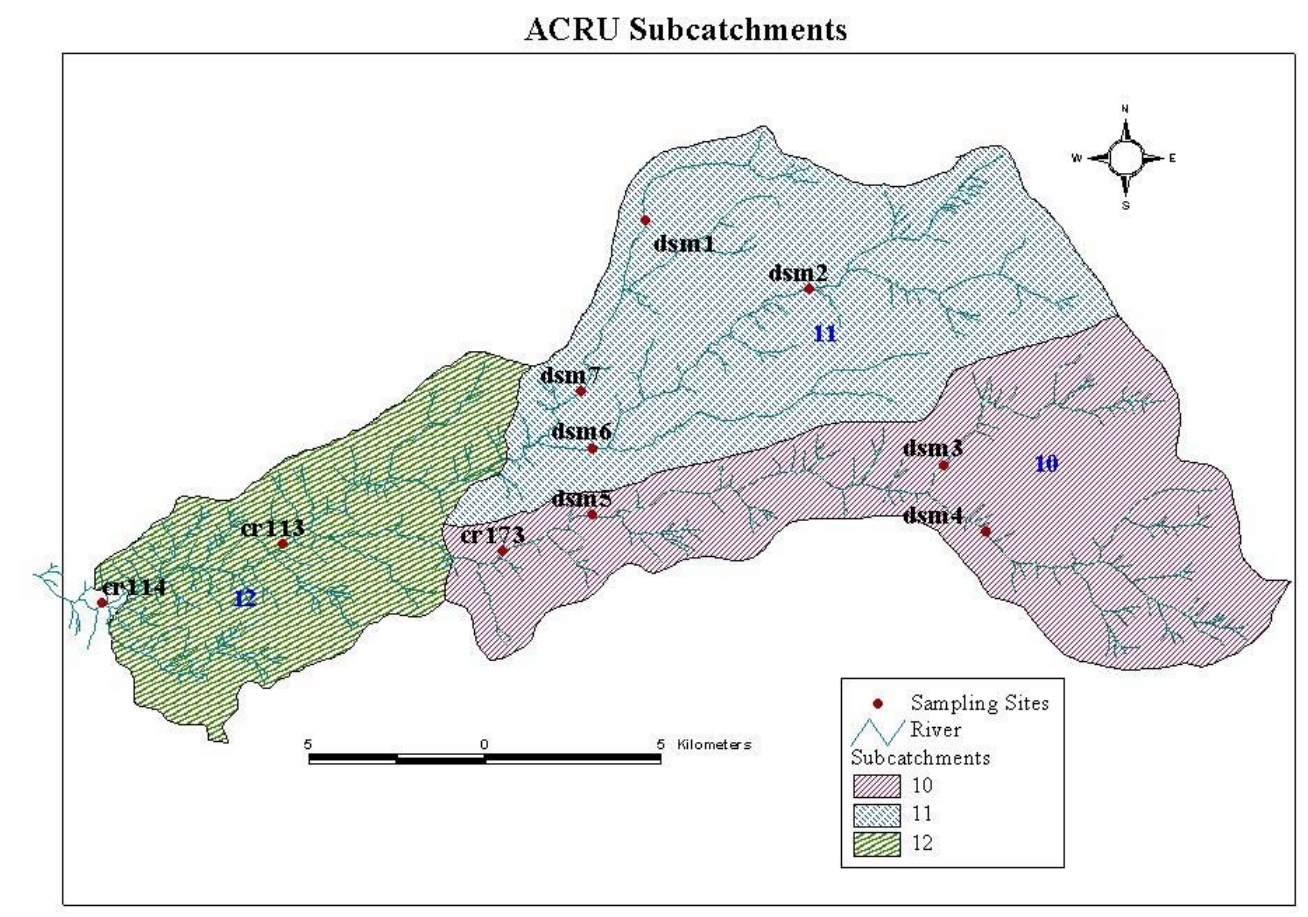

Figure 1 Muda catchment

\section{Vegetation and relief}

The Muda catchment lies in the highveld area and ranges in height from 1300 to $1500 \mathrm{~m}$ above sea level. It is, however, characterised by gently sloping terrain with slopes generally below $1^{\circ}$ in most areas. The natural vegetation in this area is composed mainly of Miombo woodland. In the Chiota Communal Area grasslands are predominant and open areas are common.

\section{Soils and geology}

The geology of the Muda catchment has a major influence on the soil formation. Generally the area has felsic rocks like granite, which results in sandy soils. Granite intrusions are common in the catchment. The area is mainly composed of paraferrallitic and othoferrallitic soils. Paraferrallitic soils are formed from granite, still have a small reserve of weatherable minerals and have sesquioxides in the clay fraction.

The soil families occurring in the Muda catchment are the $5 \mathrm{E}$ and $7 \mathrm{G}$ in a classification where the $\mathrm{E}$ family is composed of igneous and metamorphic rocks, other than basalt, that gives rise to soils of high clay content. The $\mathrm{G}$ family is composed of granites and gneissic granite that give rise to soils in which the sand fraction is course-grained. The clay content varies according to the degree of weathering and catenal position.

The soil types in Chihota are generally very poor in nutrients and depend heavily on artificial fertilisation for crop production.

\section{Land cover and land use}

Table 1 is a summary of the land cover and land uses in the Muda catchment as per the classified Landsat Thematic Mapper Image of April 1998.

In the mainly communal lands of Chiota, land is used for grazing and crop production and most of the area has been cleared for cultivation purposes. The Muda River and its tributaries are bound on either side by communal settlers who have established gardens along the banks of the rivers for horticultural crops like

\begin{tabular}{|c|c|}
\hline \multicolumn{2}{|c|}{$\begin{array}{l}\text { TABLE } 1 \\
\text { Land cover and land uses in the Muda } \\
\text { catchment }\end{array}$} \\
\hline Class name & Total \% \\
\hline Communal land & 38.00 \\
\hline Bushland & 31.70 \\
\hline Bare soil brown clayey & 11.98 \\
\hline Communal farming & 9.51 \\
\hline Ripe crops & 2.29 \\
\hline Miombo forest & 2.10 \\
\hline Bare soil sandy & 1.41 \\
\hline Unclassified & 1.33 \\
\hline High density settlement & 0.75 \\
\hline Low density settlements & 0.72 \\
\hline Wetlands & 0.01 \\
\hline Fallow & 0.15 \\
\hline Irrigated grassland & 0.02 \\
\hline Eucalypt old & 0.02 \\
\hline Eucalypt young & 0.02 \\
\hline Natural forest & 0.01 \\
\hline
\end{tabular}

tomatoes, onions and other vegetables. During the rainy season maize is also planted in the gardens as well as in the main fields.

Vegetation is sparse and mostly confined to drainage lines and rock outcrop areas. On the lower Muda catchment, there are smallscale commercial farming areas. The main land-use type is grazing for dairy and beef production in addition to crop production. Vegetation is medium to dense.

A large percentage of the land is used for communal farming and dwelling land, consists of sparse bush and bare ground and all these are prone to diffuse pollution problems. 


\section{Socio-economic conditions}

According to the 1992 population census the Muda catchment lies in six wards with a total population of 23354 people. The average population density of all these wards is 48.73 persons $/ \mathrm{km}^{2}$. Wards 1 and 3 have the highest population density of around 75 people and the lowest density is in the commercial farming areas in Ward 12 with a density of 10 persons $/ \mathrm{km}^{2}$.

\section{Environmental problems in the area}

The activities of the communal farmers in this catchment give rise to a host of pollutants, which include nitrates and phosphates from fertilisers, biocides and other poisonous residues, and eroded soil, all of which are of a diffuse nature. The major problems in the area include nutrient enrichment and siltation of water resources, which are inevitable by-products of profitable crop production (Crowder et al., 1985).

\section{Nutrient enrichment}

Fertiliser washed off by storm water runoff is the major source of nitrate and phosphate pollution of water-courses in agricultural regions. In the project area the communal farmers depend heavily on artificial fertilisation for crop production resulting in enrichment of water courses.

\section{Use of biocides}

Since the 1940s considerable amounts of organochlorine pesticides (OCPS) have been introduced into the aquatic environment. Ground spraying of biocides in horticultural gardens for pests, snails and mosquito-based diseases has become a regular feature in the catchment.

An adjunct to the use of pesticides and insecticides in agriculture is the use of herbicides to control the growth of undesirable plant species. The fate of these herbicides is not well understood in tropical water ecosystems.

\section{Soil erosion}

The most serious effect of agriculture is soil erosion. Ellwell and Stoking (1988) estimates that soil loss from agricultural catchments through erosion ranges from 1 to $20 \mathrm{t} / \mathrm{ha}$ a under conditions found in the highveld of Zimbabwe. Soil losses due to erosion contribute to the sediment load carried by the rivers and increase the siltation of dams.

It was observed that the people in the study area are no longer erecting contour ridges or strips of grass like vatva grass, which serve the function of holding back soil and water and channeling it away from the cultivated land. Without contour ridges in their fields, the applied fertilisers are washed into rivers by runoff since there is nothing to hold it or to stop sheet erosion.

Stream bank cultivation is practised generally and this causes the loosened soil to be washed into rivers aggravating the problem of siltation and nutrient enrichment from the fertilisers.

Gardens have also been established along rivers but in most instances they are located right on the banks whilst the distances of gardens should be at least $30 \mathrm{~m}$ from the streams depending on the size of the streams and the terrain.

\section{Destruction of natural resources}

The land-use practices in the study area have affected the natural resources adversely and vegetation has been destroyed through various mechanisms, which include:

- Overgrazing, which destroys all the available grass cover exposing the soil to erosion especially by the first storms when the ground is still bare.

- Uncontrolled veld fires also leave bare ground behind which gets eroded when the rains come introducing the burnt grass, loose soil and other nutrients into the rivers polluting the water; silting up the rivers and forming gullies.

- Uncontrolled cutting down of trees has removed the tree canopy, which has several functions. The trees are important for the provision of soil cover, and as a source of timber, fencing and roofing materials among many other things.

Another important ecological unit that has been affected is wetlands. Wetlands are a very important and fragile ecological unit in which a very large number of life forms exist. People in the study area tend to destroy the wetlands by ploughing them, draining them and even settling in them. Because of this very few wetlands are left in the area. The wetlands also served a function of purifying the water as it flows to the rest of the river system but this function has been interfered with and the natural purification no longer exists. Because of their fragile nature the wetlands quickly get eroded and destroyed once tampered with, so they need to be protected.

Use of inappropriate technology is also taking its toll. People in the study area are still using inappropriate technology like sledges as a form of transport. This has a problem of causing gully formation in the roads and tracks. The use of scotch-carts for transporting goods is a better alternative.

\section{Project approach}

Environmental issues are shaped by a combination of technical, social, cultural, political and economic factors. In order to solve these environmental problems an interactive, collaborative and experimental approach was adopted. This approach entails a focus that is practical in nature and not altogether scientifically rigorous, yet taking the different elements of the diverse disciplines which impact on the environment and combining them.

The approach being followed in this project is to ensure involvement of all affected sectors including those that have so far been neglected, influencing their behaviour and measuring the effects on the environment and their livelihood. This was done by encouraging close co-operation of researchers, implementers and stakeholders at the lowest level and continuously monitoring the state of the environment, with the aim of creating a common framework for communication and interaction. This approach is open and participatory and all the necessary information to make informed decisions can be obtained from the affected parties.

\section{Activities and major findings}

In developing mechanisms that can be used to influence farming and other practices, several activities were employed to develop correlations between the management practises and indicators such as water quality and crop yields. Since a source-directed approach was adopted, the successful involvement of the stakeholders was very important. However, the major constraint in rural developing areas is the availability of data. Gauging stations are very few, far 


\begin{tabular}{|c|c|c|c|c|}
\hline \multicolumn{5}{|c|}{$\begin{array}{l}\text { TABLE } 2 \\
\text { Fertiliser application rates for Muda catchment }\end{array}$} \\
\hline \multirow[t]{2}{*}{ Type } & \multirow[t]{2}{*}{ Constituents } & \multirow[t]{2}{*}{ Where applied } & \multicolumn{2}{|c|}{ Application rates (kg/ha) } \\
\hline & & & Recommended & Actual \\
\hline $\begin{array}{l}\text { Compound D } \\
\text { AN } \\
\text { Compound L } \\
\text { Compound S } \\
\text { AN }\end{array}$ & $\begin{array}{l}\text { Nitrates, phosphates and potassium } \\
\text { Ammonium nitrate } \\
\text { Nitrates, phosphates and potassium } \\
\text { Sulphur, nitrates, phosphates and potassium } \\
\text { Ammonium nitrate }\end{array}$ & $\begin{array}{l}\text { Basal for maize } \\
\text { Top-dressing for maize } \\
\text { Tomatoes and onions } \\
\text { Tomatoes and onions } \\
\text { Top-dressing for tomatoes } \\
\text { and onions }\end{array}$ & $\begin{array}{l}200-250 \\
150-200\end{array}$ & $\begin{array}{c}80-200 \\
100-150 \\
75 \\
75 \\
50-75\end{array}$ \\
\hline
\end{tabular}

apart and not where they are always needed. In the study area, there are no river gauging stations and water quality monitoring was nonexistent. So a lot of initial data-gathering and use of alternative means of generating data were employed.

A lot of development was therefore necessary to establish monitoring points. In addition, different measures were implemented to obtain information on aspects such as fertiliser application rates, farm-manure application rates, crop yield data, and the quality status of the aquatic system.

\section{Stakeholder involvement}

The stakeholder participation involved information dissemination, awareness creation, and practical implementation of agreed practises. The community was encouraged to actively take part in the decisions affecting their catchment and interactively explored alternative policies for its management without necessarily implementing new technologies but adapting what they had and managing it properly.

The study was initiated in 1998 and in the 1 st year the communal farmers were left to till, plant and harvest in their usual manner and their farm-yard manure and fertiliser application rates were noted (Table 2). In the 2nd and subsequent years, the activities of the stakeholders were influenced by conducting a series of meetings at village level throughout the Muda catchment. In 1999 ten meetings were held and at one meeting a record 300 villagers attended. In 2000 and 2002, village meetings were conducted each year and the number of attendants had been limited to 50 representatives per village, mostly the village heads, because of the overwhelming attendance of the previous year. A collaborative approach was taken and officers from the Agricultural Extension Services and Natural Resources Board were incorporated into the project team.

The village meetings comprised plenary presentations from the experts, brainstorming and question-and-answer sessions, which were all very participative. The areas covered included:

- Proper agricultural land management

- Reduction of nutrient flushes by applying fertiliser at the appropriate rates and at the right times

- Appropriate application of biocides

- Appropriate siting of gardens to avoid stream-bank cultivation

- Protection of wetlands

- Protection of grazing and forest lands.
The aim was to influence the behaviour of the community at source so that fewer pollutants are generated. To generate their interest the participants were presented with prizes of T-shirts printed with water quality slogans and a natural resource conservation competition was hosted, in which the participants were requested to put into practice what they had learnt. A panel of judges went out to the villages to inspect the conservation works. The best works were then presented with prizes again.

In this way the communal farmers became interested in the project and it was an incentive for them to implement what they had learnt.

\section{Pollution measures and indicators}

Information is scarce, as in most developing countries, and a lot of initial data gathering is required for any meaningful decisions to be made.

\section{Fertiliser application rates}

The manner in which the communal farmers were applying fertiliser was inappropriate. For instance, for top-dressing they applied all their $\mathrm{NH}_{4} \mathrm{NO}_{3}$ fertiliser at once and this often happened before storms. Split application was recommended and it was impressed upon them to avoid fertiliser application just before storms as it would all be washed away. It made economic sense to them to conserve fertiliser and apply it when required by the plants and in the right amounts.

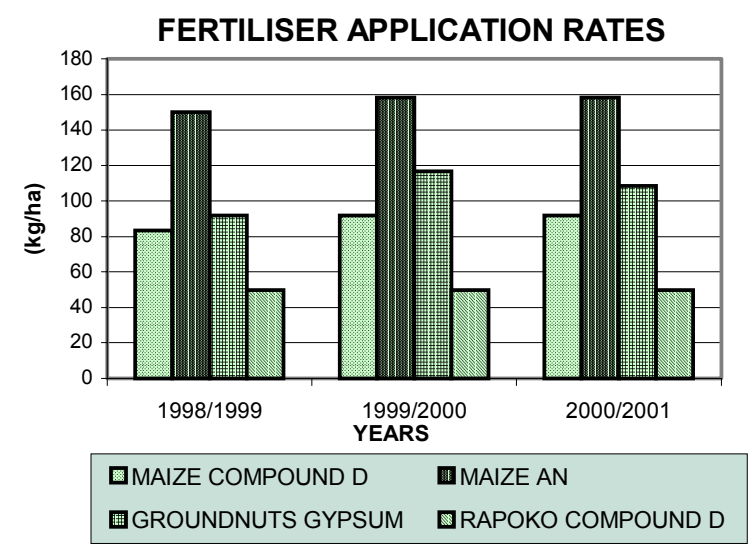

Figure 2

Fertiliser application rates 
A survey and information from the agricultural authority revealed that both basal and topdressing fertilisers are used as outlined in Table 2.

Figure 2 represents the fertiliser application rates for the past three seasons.

For maize and groundnuts, compound D, AN (Table 2) and gypsum were applied respectively. Their application rates increased from $1998 / 1999$ to $1999 / 2000$ by $10 \%$ for compound $\mathrm{D}$ from 83.3 $\mathrm{kg} / \mathrm{ha}$ to $91.7 \mathrm{~kg} / \mathrm{ha}$ and by $5.53 \%$ for AN from $150 \mathrm{~kg} / \mathrm{ha}$ to 158.3 $\mathrm{kg} / \mathrm{ha}$ on average and then remained constant to year 2000/2001. As for Rapoko, compound D was applied at the rate of $50 \mathrm{~kg} / \mathrm{ha}$ in 1998/1999 and remained constant over the project period.

The natural fertility of the soil in the study area is very low and any meaningful yields require some form of fertiliser. Soil fertility demonstrations were carried out in the area and soils were analysed and farmers advised of the status of their soils and how much fertilisers to apply to enhance nutrients. The actual applied rates are much lower than the recommended rates and this can be attributed to the high cost of fertiliser, which has gone beyond the reach of many farmers.

Application rates for farm-manure increased in t/ha from 1998/ 1999 to 1999/2000 for all crops (Fig. 3). For maize, farm manure application increased by $3.33 \%$ from 7.5 t/ha in 1998/1999 to 7.75 t/ha in 1999/2000. It increased by a further $16.12 \%$ to $9 \mathrm{t} / \mathrm{ha}$ in 2000 / 2001. For groundnuts, farm manure application rates increased by $38.4 \%$ from $5 \mathrm{t} / \mathrm{ha}$ in $1998 / 1999$ to $6.92 \mathrm{t} / \mathrm{ha}$ in $1999 / 2000$ and increased further by $15.61 \%$ to $8 \mathrm{t} /$ ha in $1999 / 2000$. For Rapoko the

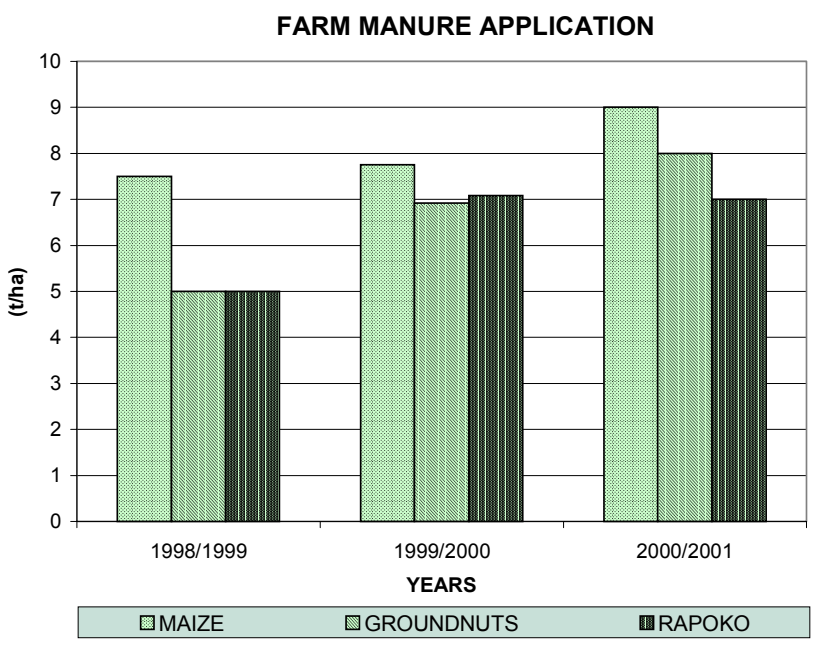

Figure 3

Farm manure application rates rate increased by $41.6 \%$ from $5 \mathrm{t} / \mathrm{ha}$ in $1998 / 1999$ to $7.08 \mathrm{t} / \mathrm{ha}$ in $1999 / 2000$ and decreased by $1.13 \%$ to $7 \mathrm{t} / \mathrm{ha}$ in $2000 / 2001$. This trend could be attributed to the further reduction in the natural soil fertility and the increase in the price of fertilisers, which has forced farmers to turn to organic manure.

There was a general decrease in the yield of all crops except paprika as shown in Fig. 4.

For maize, the crop yield in tonnes per hectare decreased from $2.2 \mathrm{t} / \mathrm{ha}$ in $1998 / 1999$ to $1.7 \mathrm{t} / \mathrm{ha}$ in $1999 / 2000$ and by a further $22.73 \%$ to $1.3 \mathrm{t} / \mathrm{ha}$ in $2000 / 2001$. For groundnuts, the yield also decreased from $1 \mathrm{t} / \mathrm{ha}$ in 1998/1999 to $0.88 \mathrm{t} /$ ha in 1999/2000 and further to $0.68 \mathrm{t} / \mathrm{ha}$ in $2000 / 2001$. The same trend was witnessed for rapoko, bambara and cow peas where yields continued to decrease with the increase in years. This trend could be attributed to the fertiliser application rates within the same area. With each crop, the soil's natural fertility decreases due to leaching and therefore more fertilisers and farm manure should be applied to enhance the soil's nutrients if it is to continue being productive.

\section{Pollution loads}

Very little flow data are available in the study area and to generate pollutant loads the flow was computed from rainfall data using the ACRU model (Schulze, 1995). ACRU is an agro-hydrological modelling system based on physically measurable or derivable catchment characteristics. Inputs to the model included the catchment area, location, altitude, catchment configuration, daily rainfall, mean monthly evaporation, minimum and maximum temperature, land cover, soil texture, soil depth. The generated stream-flow data were used to run the model and to estimate

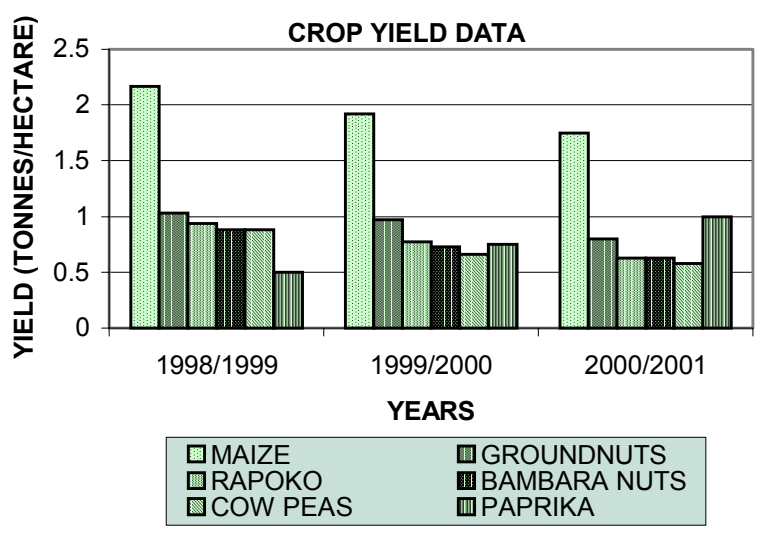

Figure 4

Crop yield data

\section{Rainfall (mm)}

Figure 5

Rainfall trends in the study area

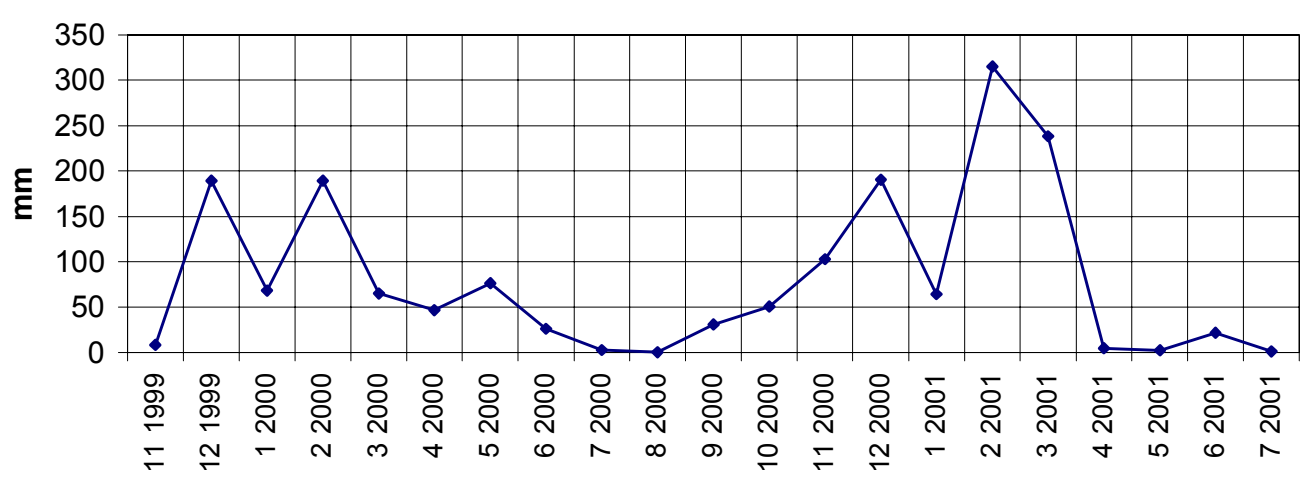

DATE 


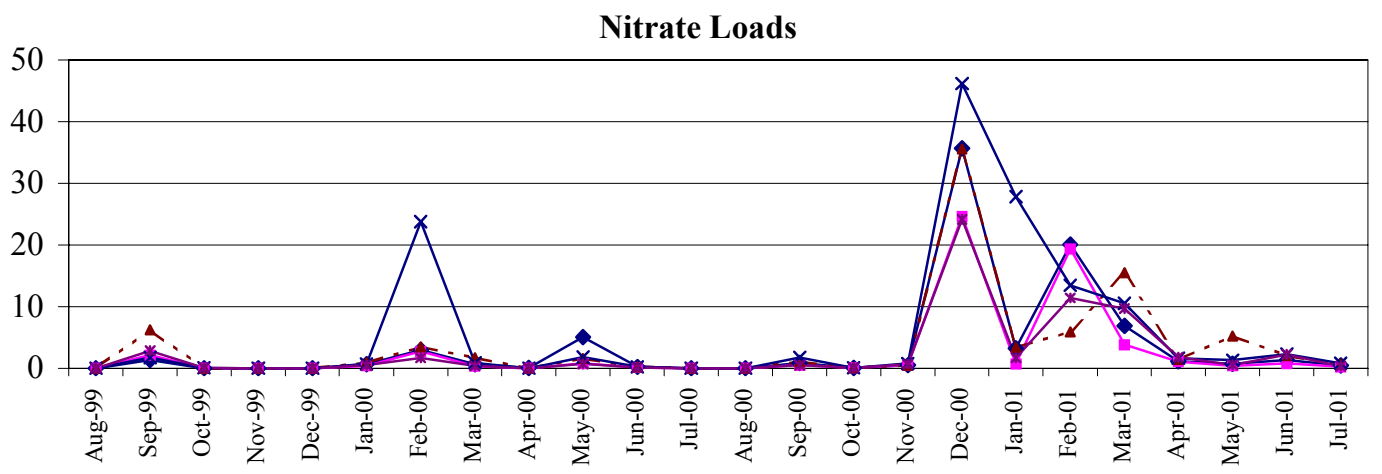

Figure 6

Trends in nitrate

loads

\begin{tabular}{|c|c|c|}
\hline$\longrightarrow$ Nitrate Loads(DSM6) & $\longrightarrow-$ Nitrate Loads(DSM7) & $--\_-$Nitrate Loads(CR113) \\
\hline$\longrightarrow$ Nitrate Loads(CR114) & $\longrightarrow$ — Nitrate Loads(CR173) & \\
\hline
\end{tabular}

Phosphate Loads

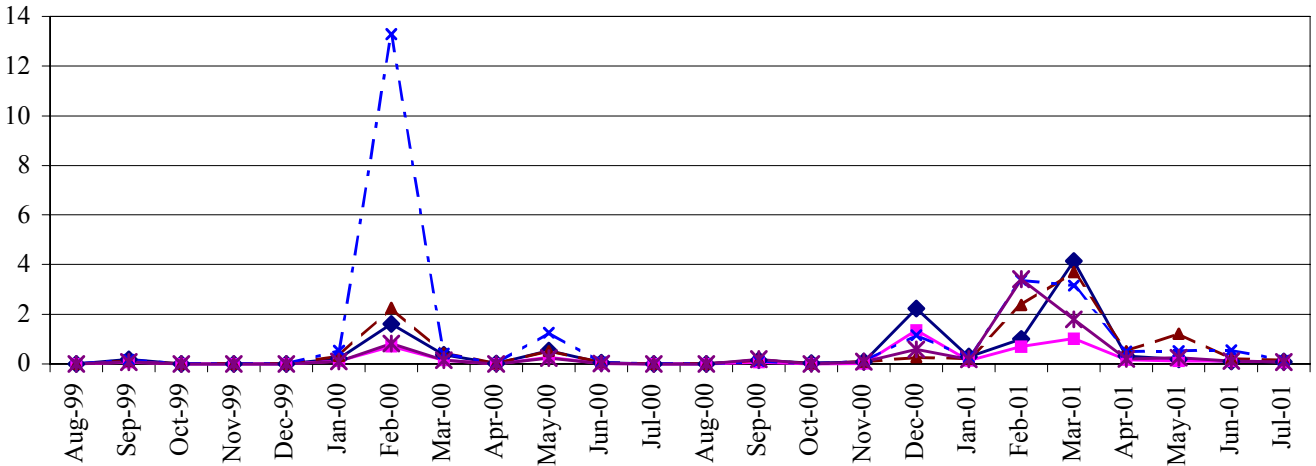

Figure 7

Trends in phosphate loads

$$
\begin{array}{ll}
\longrightarrow \text { - Phosphate Loads(DSM6) } & \longrightarrow \text { Phosphate Loads(DSM7) } \\
\rightarrow-\text { Phosphate Loads(CR113) } & --\star-- \text { Phosphate Loads(CR114) } \\
\longrightarrow \text { - Phosphate Loads(CR173) } &
\end{array}
$$

discharge for the three subcatchment areas. Most of these data were obtained from an automatic weather station at Mahusekwa (a growth point in the study area) and the soil data were obtained from soil surveys of the study area. Figure 5 depicts the rainfall pattern in the area during the study period.

The 1998/1999 season started off with good early rains in September. There was very little rain in December and the rains started again in January up to the end of March. The total rainfall was $764 \mathrm{~mm}$.

For the 1999/2000 season the rainfall distribution during the initial stages of crop production was erratic with heavy downpours in January. The total rainfall was $960 \mathrm{~mm}$.

For the 2000/2001 season continuously heavy downpours were received during the months of January and February. The total rainfall was $960.5 \mathrm{~mm}$.

For water quality monitoring the catchment was divided into three subzones; 10, 11, and 12 (Fig. 1 ). A monitoring programme was set up and a set of ten sampling sites was established as shown in Fig. 1. Water quality samples were then collected from these sites on a weekly basis and analysed for nitrates, phosphates, total suspended solids (TSS) and dissolved solids (DS). The nitrates and phosphates were analysed spectrophotometrically, the TSS was analysed by measuring the dry mass of the material that is removed from a measured volume of a water sample by filtration through a standard filter and the DS was analysed by evaporating the samples to dryness and determining the mass of the residue.
Pollutant loads where then computed from the water quality analytical results and the discharge estimates. The pollutant flushes from each subzone were then determined using points DSM 6 and DSM7; CR173 and CR114, which are at the exit of each subzone, in the catchment. Figures 6 to 9 are a summary of the trends for nitrates, phosphates, TSS and DS observed over the project period.

The current observed trends indicate that nutrients and sediments are flushed from the Muda catchment in line with fertiliser application by the farmers and the rainfall pattern. The sediment yields were high throughout due to lack of ground cover especially at the onset of the rainy seasons.

The pollutant load trends were influenced by the rainfall and runoff patterns and increased over the project period in line with the increases in precipitation (Fig. 5). The peaks also correspond to the fertiliser application periods. Although the nitrate levels were mostly below the recommended limits for discharge, such levels have been found to cause impoundments to become eutrophic (Sakupwanya, 1991).

\section{Conclusion}

An interactive and participative approach for monitoring and managing non-point source pollution problems in a semi-arid region has been investigated by working closely with the people directly affected, in order to formulate strategies to minimise the pollutants being flushed out of the catchment. The current observed 
Figure 8

Trends in suspended solids loads

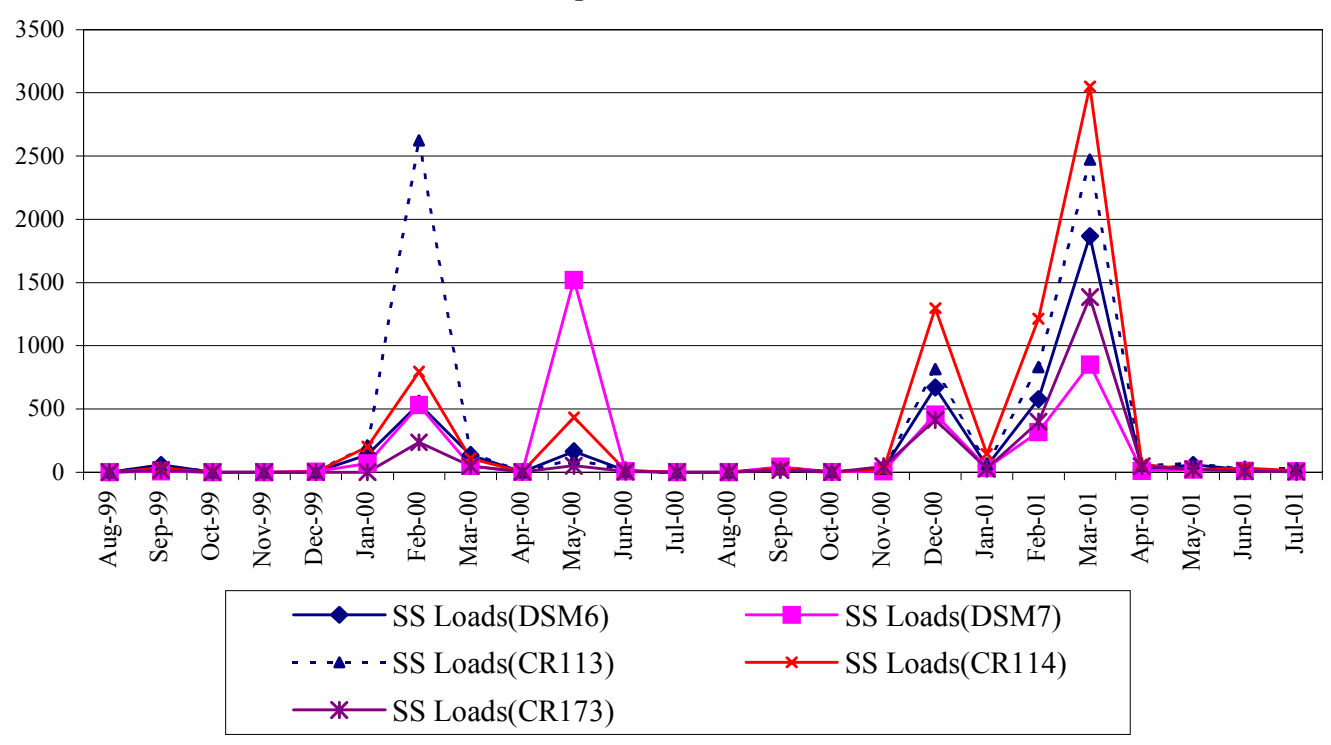

Dissolved Solids Loads

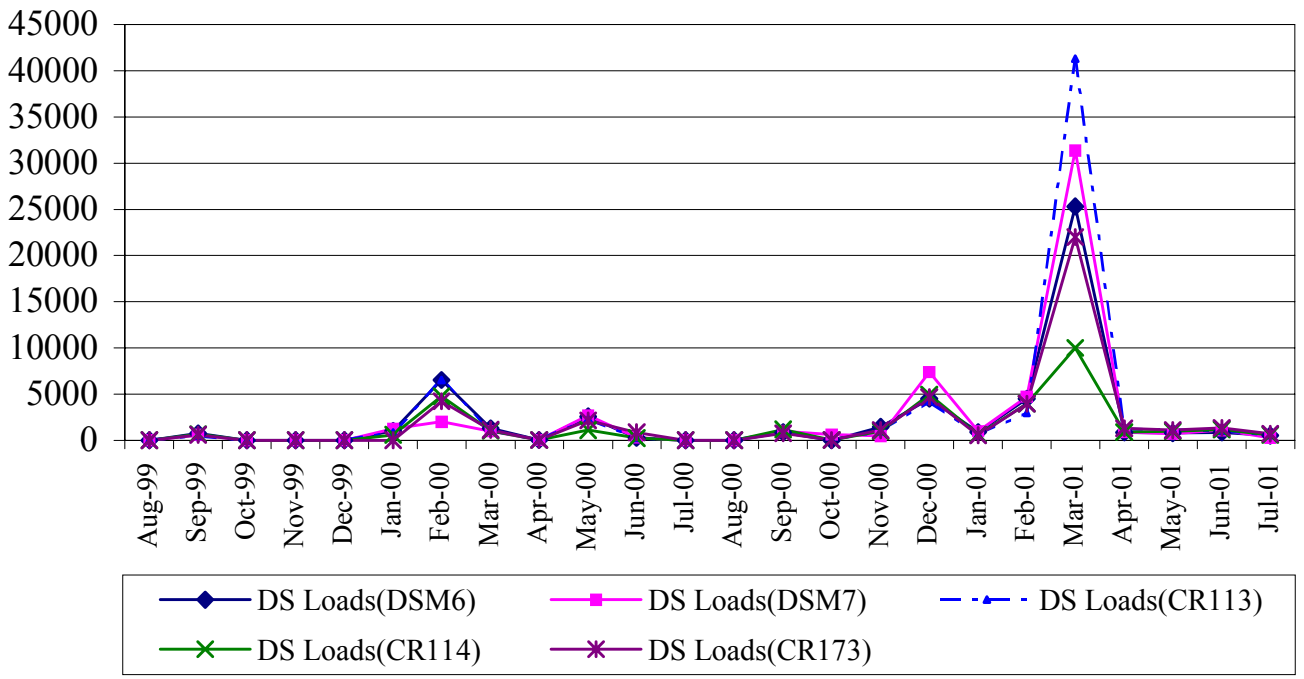

trends indicate that nutrients and sediments are being released from this catchment mainly because of the heavy dependence of the communal farmers on fertiliser application for crop production. These nutrients end up in the impoundments along the length of the Sanyati catchment, a major contributor to the waters of Lake Kariba, which is already facing eutrophication problems. Dealing with the problem at the headwaters of such a catchment goes a long way in reducing the nutrient and sediment loads and protecting the quality of water for downstream users.

A major deduction that can be made from the surveys and water quality monitoring that has been carried out over the study period is that pollutant loads were influenced to a greater extent by the changes in the rainfall and runoff patterns than by the changes in agricultural practices. Improved farming practices may result in lower pollution under normal conditions, but the erratic rainfall patterns and the flash floods like the ones that had been experienced over the last two seasons, displayed marked influences on the pollutant loads. For instance, the heavy downpours which were witnessed especially in 1999/2000 rainy season due to the cyclone "Eline", resulted in excessive leaching and eroding of nutrients resulting in high pollutant flashes and reduced crop yields.
Although fertiliser application rates have increased as a result of soil tests and agronomic advice, this did not affect the crop yields positively as the yields decreased over the study period. The yields were actually affected by the erratic rainfall patterns which are characteristic of semi-arid regions.

The water quality and sediment data during the study period could not be used as an indicator of the success of the programme as they were affected and influenced by many other factors. Also sediment yields did not show any signs of reduction. This was to be expected, since re-vegetation and conservation works only show positive effects after a long time of implementation of the programmes.

However, the community's awareness has been raised and they are taking steps to implement the outcomes of the community meetings. The effects of other practices like neglecting contour ploughing and stream bank farming were demonstrated to them by the sediment loads and the siltation that has affected their rivers. Some of their fields have now lost much of its top soil, a fact they testified to. The farmers were encouraged to practise contour ploughing and the use of strips of vertiva grass to prevent sheet erosion. 


\section{References}

CROWDER BM, PIONKE HB, EPP DJ and YOUNG CE (1985) Using CREAMS and economic modeling to evaluate conservation practices: An application. J. Environ. Qual. 14 (3).

DUDA AM (1993) Addressing non-point sources of water pollution must become an international priority. Water Sci. Technol. 28 (3-5) 1-11.

ELLWELL HA and STOKING MA (1988) Loss of soil nutrients by sheet erosion. The Zimbabwe Sci. News 22 (7/8).

FEDRA K (1984) Interactive water quality simulation in a regional framework: A management oriented approach to lake and watershed modelling. Ecol. Modell. 21 209-232.

HOFFMANN JR (1994) Non-point Source Pollution in the Hennops River Valley. Water Research Commission Report No. 518/1/95, Pretoria, South Africa.
ONGLEY ED (1998) Modernisation of water quality programmes in developing countries: Issues of relevancy and cost efficiency. Water Quality Int., September/October.

SAKUPWANYA JK (1991) A Bayesian Decision Analysis Approach to Controlling Non-Point Source Nitrate Pollution of Groundwater. Ph.D. Thesis, Gueiph Univ., Guelph, one. N1G 2WI, Canada.

SCHULZERE (1995) Hydrology and Agrohydrology: A Text to Accompany the ACRU 3.00 Agrohydrological Modelling System. Water Research Commission, Pretoria, Report TT 69/95.

SHELA ON (1993) Challenges of water quality monitoring in Southern African Development Community. UNESCO/SADC-ELLMS Water Quality Workshop, Harare, Zimbabwe 